Just as literature can be used as a means of understanding the inner life of others as well as ourselves (Oyebode, Psychiatric Bulletin, April 2002, 26, 121122), articles such as these autobiographical narratives deepen our understanding of individual experiences, and facilitate our engagement of patients and carers on a more intimate level. The Department of Health (2001) has emphasised the importance of user and carer involvement in mental health services at a variety of levels e.g. service delivery, training and research. Some may be sceptical of user involvement (Tyrer, Psychiatric Bulletin, October 2002, 26, 406-407), but I am looking forward to my higher specialist training as patients and carers become involved in enriching the learning experience of all psychiatrists.

DEPARTMENT OF HEALTH (2001) Involving Patients and the Public in Healthcare: A Discussion Document. London: Department of Health

Nicole Karen Fung SHO in Psychiatry, Queen Elizabeth Psychiatric Hospital, Edgbaston Birmingham B15 2QZ

\section{Malignant Alienation - a concept that has not yet arrived?}

I read with interest the article by Graham et al regarding addressing carer attitude to difficult patients (Psychiatric Bulletin, July 2004, 28, 254-256). The uptake of new concepts like malignant alienation into mainstream teaching and practice depends on a number of factors, including usefulness and comprehensibility. We described malignant alienation in detail a decade ago (Watts \& Morgan, 1994). Strategies were documented for preventing and managing the alienation process for difficult patients on psychiatric wards with the specific aim of reducing inpatient suicide. However, despite knowing much about the nature of inpatient suicide, malignant alienation is not found in the latest editions of any of the leading standard UK postgraduate textbooks.

My own recent small postal survey of consultant psychiatrists in one teaching area (16 surveyed, 12 responded) found that more than half knew it was not taught to their trainees and a third felt it had not informed their own practice. It seems that the concept is not taught widely and is applied patchily, but why? Malignant alienation is acknowledged as a useful concept from forensic units (Torpy, 1994, personal communication) through to learning disability. The weight of its psychological components may have led to a slower uptake within units where a biomedical approach is prevalent, and this explanation is reinforced from my own survey which suggested the presence/ absence of a consultant psychotherapist (or similar champion) was pivotal in psychological concepts gaining credibility or not. Or perhaps avoidance of the powerful negative feelings at the heart of the alienation process itself still continues to explain its omission from standard teaching?

WATTS, D. \& MORGAN, G. (1994) Malignant alienation: dangers for patients who are hard to like. British Journal of Psychiatry, 164, 11-15.

Darryl Watts Handley Cross House, Harewood End, Herefordshire HR2 8JT

\section{The nuts and bolts of repatriating patients}

We read with interest the review article by Gordon et al (Psychiatric Bulletin, August 2004, 28, 295-297) on air travel by passengers with mental disorder. We would like to share our experience of the difficulties in assessing a patient and the process involved in repatriation.

Our patient was from an Eastern European country, which recently became a member of the European Union. She was admitted with a history of aggression and bizarre behaviour. Gordon et al emphasise that assessment of fitness to travel is essential. However, this can prove to be difficult in individuals who do not speak English as the understanding and interpretation of symptoms in psychiatry is not consistent across languages. In spite of efforts to assess our patient through an interpreter, we were not entirely sure of the psychopathology, diagnosis and risks involved. Our working diagnosis was of one of a psychotic disorder, she was treated with neuroleptics. There was limited improvement.

The patient persistently asked to be repatriated. This left us in a dilemma as to whether we should continue her treatment in the unit or repatriate her. On the one hand, we were uncertain of the services in her country and her suitability for travel, but on the other hand her persistent request to return home was making her worse. We eventually decided that it was in her best interest to be repatriated. There was a substantial delay between the time when we decided to repatriate and the actual departure. This was due to a number of reasons including: initially the wrong form being requested by the insurance company (E107, which does not exist); lack of communication directly with the insurance company; and uncertainties as to whose responsibility it was to make the travel arrangements and meet the costs

We found an official from the patient's Consulate in London to be of invaluable aid. They were useful in liaising with the insurance company, identifying the correct form (E111) that authorises expenditure for treatment and repatriation and arranging for someone to meet the staff and the patient at the destination point.

Reports were provided for the insurance company and the airlines. The airlines made us aware that travel arrangements would be more complicated if medication was required during the flight. The travel arrangements were made by the trust management team. Eventually, the patient was repatriated successfully. We were left feeling exhausted, but learned from our ordeal.

*R. Arif Special Registrar in Psychiatry, Lyndon Clinic, Hobs Meadow, Solihull B92 8PW

P. C. Naik Consultant Psychiatrist, Lyndon Clinic, Solihull 